\title{
Performance Improvement of Truck Assembly Line through Modeling and Simulation Using Arena Software
}

\author{
Bi-Foua Tanguy Emmanuel Lorou', Peter N. Muchiri2, Patrick Kuloba ${ }^{3}$, James K. Kimotho ${ }^{3}$ \\ ${ }^{1}$ Department of Mechanical Engineering, Pan African University of Basic Science Technology and Innovation, Nairobi, Kenya \\ ${ }^{2}$ Department of Mechanical Engineering, Dedan Kimathi University of Technology, Nyeri, Kenya \\ ${ }^{3}$ Department of Mechanical Engineering, Jomo Kenyatta University of Agriculture and Technology, Nairobi, Kenya \\ Email: tanguylorou@gmail.com
}

How to cite this paper: Lorou, B.-F.T.E., Muchiri, P.N., Kuloba, P. and Kimotho, J.K. (2021) Performance Improvement of Truck Assembly Line through Modeling and Simulation Using Arena Software. Open Journal of Optimization, 10, 88-100. https://doi.org/10.4236/ojop.2021.103007

Received: July 28, 2021

Accepted: September 26, 2021

Published: September 29, 2021

Copyright (C) 2021 by author(s) and Scientific Research Publishing Inc. This work is licensed under the Creative Commons Attribution International License (CC BY 4.0).

http://creativecommons.org/licenses/by/4.0/

(c) (i) Open Access

\begin{abstract}
Due to global completion in the automotive industry, productivity improvement is vital in these industries. In automotive assembly lines, productivity loses are attributed to bottlenecks, long processing time in workstations and underutilization of resources. The purpose of this research is to evaluate the performance of the production system, analyze the bottlenecks in different parts of the workstation, their capacity and constraints. Also, develop different scenarios for improvement. To achieve this objective, a simulation model was developed using Arena Software to analyze bottlenecks in each workstation. The analysis was based on the queue in the system to identify the longest queue in workstations. After analysis of the assembly line, the result showed that the longest waiting time observed is cab preparation and drop, bumper, engine subassembly fitment of soundproof with respective numbers 14.4, 13.97, $13.00,13.70$ minutes, with respective average number waiting of $24.87 \%$, $17.57 \%, 25.91 \%$ and $23.39 \%$. Using different scenarios for the improvement of the production line showed that the waiting time observed in-cab preparation and drop, bumper, engine subassembly, fitment of soundproof has greatly reduced for the two workstations added and three operators respectively from 14.4 to 3.97 and 3.1, from 13.97 to 3.77 and 2.48 , from 13.00 to 4.21 and 3.83, from 13.70 to 0.00 and 2.37 minutes, with respective average number waiting from $24.87 \%$ to $5 \%$ and $2 \%$, from $17.57 \%$ to $5 \%$ and $0.9 \%$, from $25.91 \%$ to $5 \%$ and $4 \%$, and from $23.39 \%$ to $0.00 \%$ and $3 \%$. To conclude the research study was able to demonstrate the modelling approach using simulation for analysis of a production line assembly. The contribution of this research was so enormous, this study has improved the output production up to $144 \%$.
\end{abstract}




\section{Keywords}

Simulation, Arena, Productivity, Automotive Industry

\section{Introduction}

The purpose of productivity improvement in the manufacturing system is to enhance efficiency of employees, machines and other devices and equipment, nature of raw material in the whole production system. Due to global competition in the automotive industry, productivity improvement remains the key challenge to be competitive and generate profits.

\subsection{Production System and Productivity}

Production is described as the gradual conversion of one form of material into another form by a chemical or mechanical process to create or improve the utility of the product for the user. It is the activity by which resources, circulating within a defined system, are combined and processed in a controlled manner to provide added value in conformity with policies communicated by management [1].

Productivity is commonly defined as the ratio between the outputs to inputs [2], it measures the relationship between outputs such as goods and services produced, and inputs that include labor, capital and other resources.

Ndungu et al. [2] emphasizes that productivity is an essential factor of economic prosperity: higher productivity leads to higher production and the standard of living in the country is directly proportional to the country's production levels. With more productivity, a country is able to export and earn foreign currency that amortizes its exchange rate.

Lanna et al. [3] describes productivity as an overall measure of the ability to produce a good or service. Productivity can also be defined as an index measuring output (goods and services) relative to the input (labor, materials, energy, etc., used to produce the output).

\subsection{Improvement Methods}

Simulation is widely used for process improvement analysis and as a tool to solve many problems in manufacturing leading to improvements efficiency, cost reduction and increased profitability. A simulation is a model that imitates reality. Basic steps in a simulation study include; formulating the problem, building the simulation model, running the model and analyzing the output [2]. Some improvements methods are based on a mathematical description of the process function to be optimized. However, it is difficult for automated manufacturing systems that manage in real time to describe complex control functions using mathematical functions.

B. O. Svensson et al. [4] Described simulation-based optimization as a method 
to be used when we have a complex system. For this purpose, it is necessary to use simulation to evaluate the performance for each set of parameter values. States that an essential feature of simulation-based optimization, compared to mathematical programming, is that of simulation the objective function is not explicitly known, in fact, this function is defined by the simulation model.

Furthermore, Spieckermann et al. [5], in their study developed a method for improvement for a body shop in the automotive industry. The research was focused on the body shop which requires to be set up every year, therefore the main issue was to find an efficient method to fulfill the layout and optimize the cycle time. In this study, the improvement was done based on a mathematical formulation and an automated optimization approach. The model was based on metaheuristics and genetic algorithm to improve the body shop. The result showed that metaheuristics combined with genetic algorithm were able to detect solutions that cannot be done manually.

Bin et al. [6] in their study addressed a small set of industrial issues using arena simulation. The simulation was based on manufacturing system design at two different stages: supply chain and assembly plant. The simulation was used to reduce manufacturing time and to increase productivity in a company offering spares for light and heavy vehicles in North America.

Furthermore, Jayaraman et al. [7] used discrete event simulation to design automotive powertrain manufacturing systems. The study was focused on a small part of the engine final assembly and repair area. The test was carried on a buffer with engines circulating continuously and entering into a test stand, or a buffer becomes available. The result showed an efficient optimization of the number of stands arrangement. The result showed much time saved using the simulation process and can be implemented for an entire system in the supply chain and production system.

A study by Marsudi et al. [8] used Arena software to simulate a production system of a metal stamping industry. This study focused on evaluating the efficiency and utilization of the production line based on processing time and time utilization in each process; for the evaluation, data was collected through observation in three workstations performing ten different processes to produce a single product.

Another study was based on the production line of a meat processing industry using ARENA software to evaluate the production line [9]. This study was conducted in Turkey to improve the production line due to growing demand. The manufacturing system turns raw meat into a ready to eat the product. Therefore, to improve the production line, different scenarios were used to produce more products using the same working time. The model evaluated the rates of machines and their utilization. The result of this research assisted the company to make the right choice based on different scenarios developed.

In different literature it was demonstrated that production improvement remains a main challenge for automotive industry to be competitive in global market. Therefore, different tools were used for simulation and visualization be- 
fore implementation in an actual system.

This study is based on a case study from a X truck final assembly line. An analysis of the final truck assembly was made through observation of different process during the production. The problem was to identify bottlenecks in the assembly line to improve product performance. An analysis was carried out, and secondary data were used to develop a conceptual model. The simulation model framework in Figure 1 describes different steps taken to conduct this study.

\section{Methodology}

This study is based on a case study from an $\mathrm{X}$ truck final assembly line. The model was based on a $\mathrm{x}$ company final truck assembly line to model, simulate and analyze bottlenecks in the production line.

\subsection{The Modelling Approach}

This section represents the conceptual model of a final truck assembly line. The conceptual model was based on an observation of $\mathrm{X}$ truck assembly line. The truck assembly line of the manufacturing processes consists of 12 processes. Three types of data were collected during this study. The first is the layout of the final assembly line of a truck as described in Figure 1.

\subsection{Model Development in ARENA}

The process plant map and the processing time was developed using arena software to analyze the throughput of the final assembly line in the automotive industry. The simulation was run for 24 hours using arena simulation software to yield the output of the process assembly line. For easier visualization, the entity was represented with trucks images to demonstrate the manufacturing process and see any queue in the system. Queues demonstrate the station is blocked and process with longer queue has higher processing time. Figure 2 shows the simulation model running in the process. The simulation was made using secondary data and follow an exponential distribution as shown in Table 1. The second data is the operating time in each workstation used to simulate the model. This data is a secondary data collected published by M. dewa et al. [10].

\subsection{Model Validation}

The simulation model has 05 main workstations with an initial output production of 16 trucks day. Through the simulation using ARENA software, the production improved from 16 trucks to 39 trucks, which is $144 \%$ improvement in the productivity. To validate the simulation model, a comparison was made using data published by [11] who also conducted research in truck assembly line with also 05 main workstations and simulate using ARENA software have showed that a simulation model using Arena has improved the production to 93\% higher than the initial model. Also, the cycle time reduced from 20 minutes per product to 8 min per product. Furthermore [12]. their study supported our 


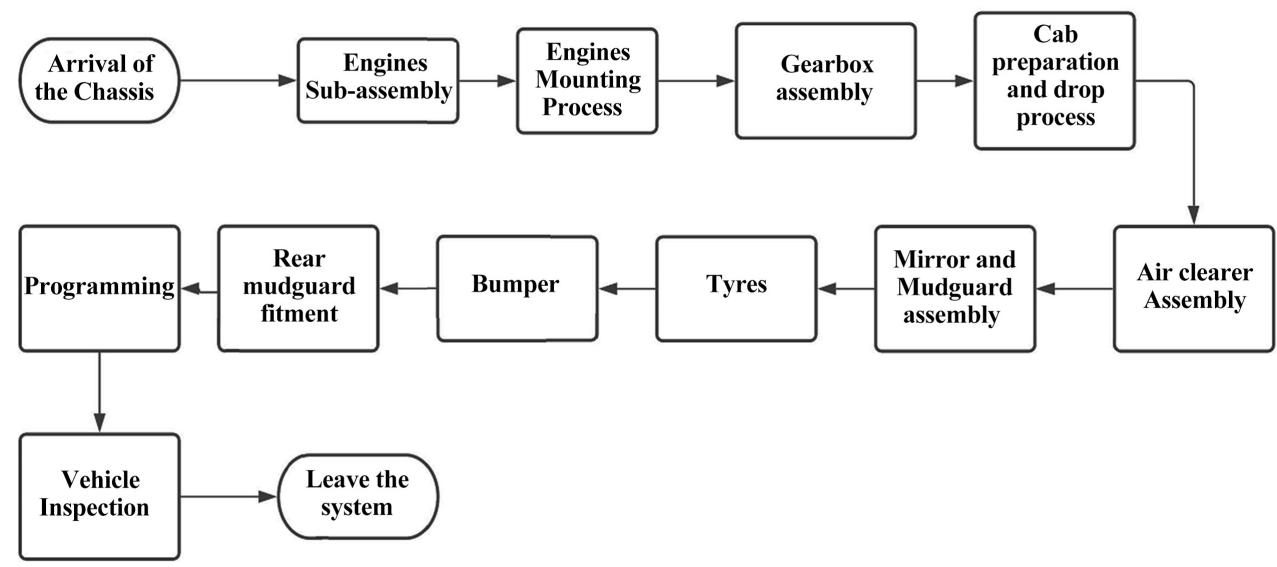

Figure 1. Conceptual model of the Truck Assembly line.

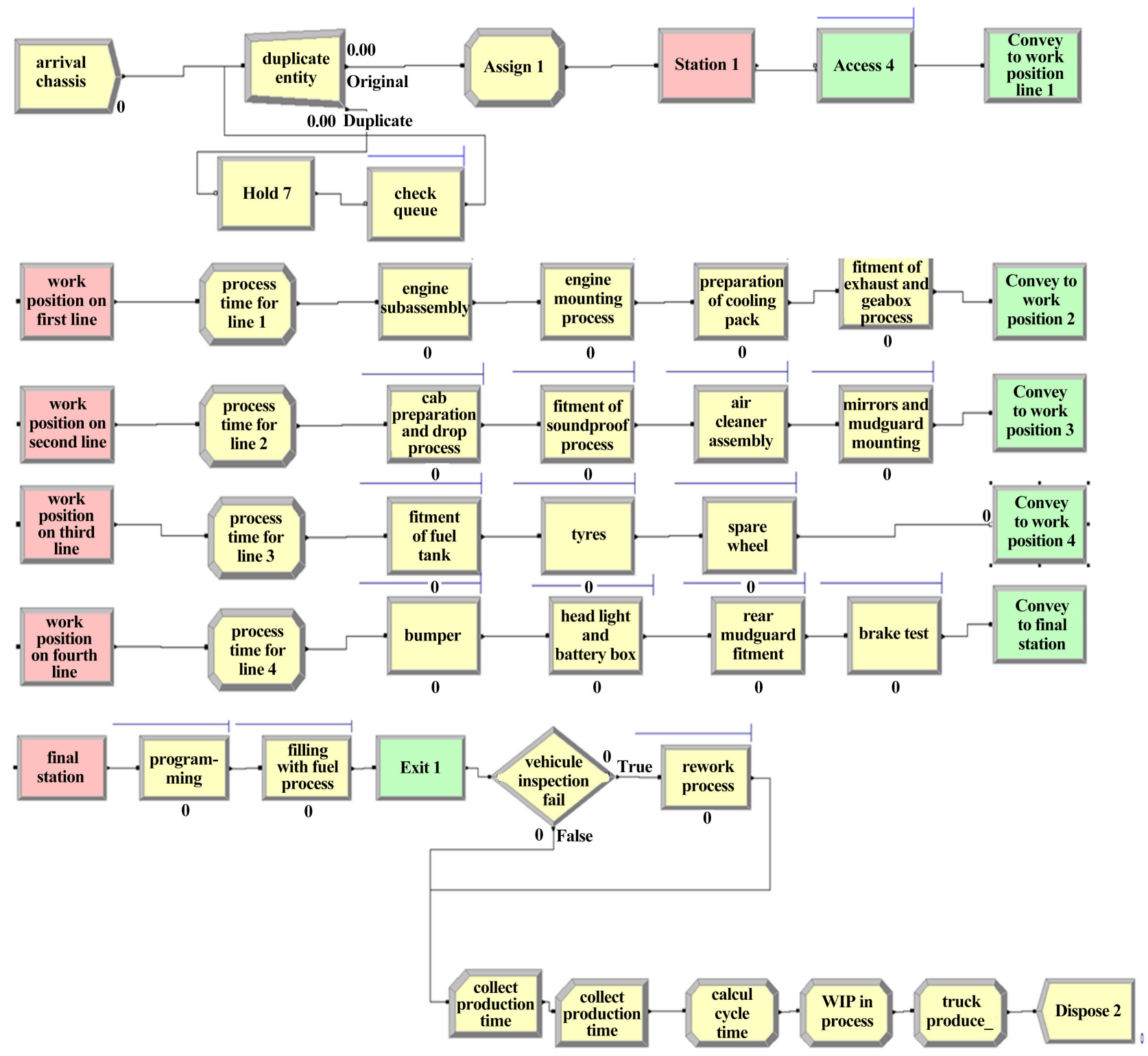

Figure 2. Simulation model in Arena (run mode). 
Table 1. Processing time in each workstation.

\begin{tabular}{|c|c|}
\hline Station & Processing time (min) \\
\hline Engine subassembly & Expo (7) \\
\hline Engine mounting & Expo (8) \\
\hline Preparation of cooling pack & Expo (6) \\
\hline Fitment of exhaust and gearbox & Expo (8) \\
\hline Cab preparation and drop & Expo (10) \\
\hline Fitment of soundproof & Expo (11) \\
\hline Air cleaner assembly & Expo (9) \\
\hline Mirror and mudguard mounting & Expo (12) \\
\hline Fitment of fuel tank & Expo (12) \\
\hline Tyres & Expo (14) \\
\hline Spare and wheel & Expo (15) \\
\hline Programming process time & Expo (6) \\
\hline Filling with fuel & Expo (6) \\
\hline Rework & Expo (10) \\
\hline Bumper & Expo (12) \\
\hline Head light and battery box & Expo (13) \\
\hline Rear mudguard fitment & Expo (12) \\
\hline Brake test & Expo (11) \\
\hline
\end{tabular}

research by improving a truck assembly line using ARENA software and implemented in a real process. Their results showed that the optimal scenario led to a $110 \%$ improvement in productivity in the simulation and $60 \%$ increase in actual daily production average. Therefore, based on these comparison, we can conclude that the model is valid and imitate a real process.

\section{Result and Discussion}

\subsection{Simulation Model}

Figure 3 shows the truck produced in a final assembly line using the initial model. It is observed that 16 trucks were produced during this simulation period.

Figure 4 shows the queue in the system in terms of waiting time and number waiting. The longest waiting time observed is cab preparation and drop, bumper, engine subassembly fitment of soundproof with respective numbers 14.4, 13.97, $13.00,13.70$ minutes, with respective average number waiting of $24.87 \%, 17.57 \%$, $25.91 \%$ and $23.39 \%$. A queue means the process is blocked by the previous one. With this data, we can conclude that cab preparation and drop, bumper, engine subassembly, and soundproof fitment are the constraints in the system. 


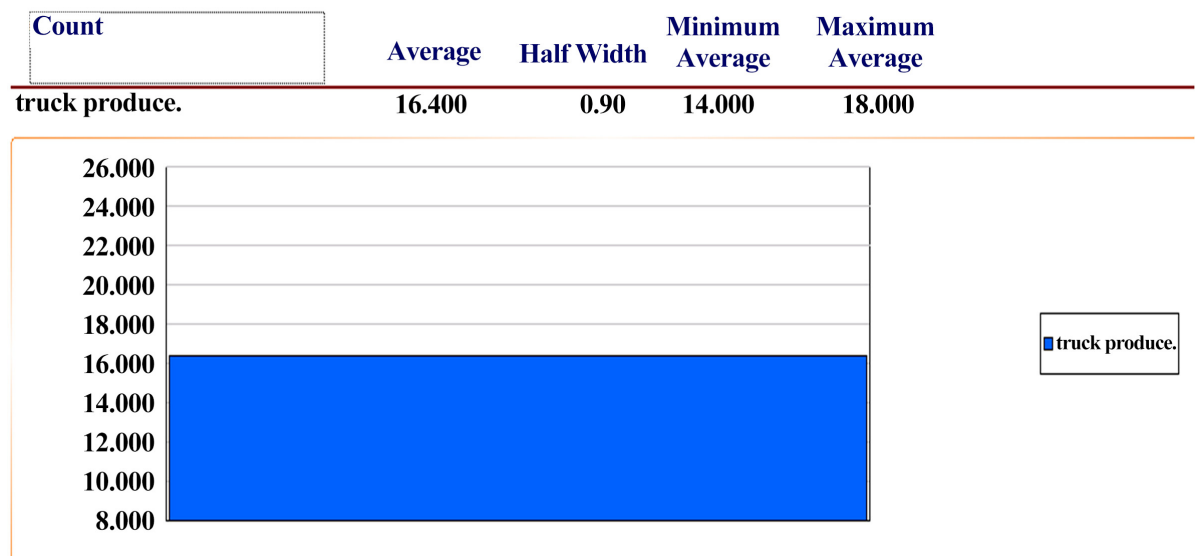

Figure 3. Number of trucks produced.

\begin{tabular}{|c|c|c|c|c|c|c|}
\hline \multicolumn{7}{|l|}{ Queue } \\
\hline \multicolumn{7}{|l|}{ Time } \\
\hline Waiting Time & Average & Half Width & $\begin{array}{l}\text { Minimum } \\
\text { Average }\end{array}$ & $\begin{array}{r}\text { Maximum } \\
\text { Average }\end{array}$ & $\begin{array}{l}\text { Minimum } \\
\text { Value }\end{array}$ & $\begin{array}{r}\text { Maximum } \\
\text { Value }\end{array}$ \\
\hline Acces 4. Queues & 526.23 & 14.37 & 501.31 & 526.65 & 0.00 & 792.14 \\
\hline air cleaner assembly.Queue & 7.7212 & 1.27 & 4.1481 & 10.5017 & 0.00 & 108.27 \\
\hline Brake test.Queue & 4.3771 & 1.14 & 1.9533 & 6.9427 & 0.00 & 80.8264 \\
\hline bumper.Queue & 13.9677 & 1.00 & 11.8343 & 15.8705 & 0.00 & 95.3781 \\
\hline $\begin{array}{l}\text { cab preparation and drop } \\
\text { process.Queue }\end{array}$ & 14.4072 & 1.00 & 11.0751 & 15.6065 & 0.00 & 100.77 \\
\hline check queue.Queue & 0.00 & 0.00 & 0.00 & 0.00 & 0.00 & 0.00 \\
\hline engine mounting process.Queue & 5.7131 & 0.59 & 4.8181 & 7.3025 & 0.00 & 59.9036 \\
\hline engine subassembly.Queue & 13.0098 & 0.84 & 11.0107 & 14.9435 & 0.00 & 82.7388 \\
\hline filling with fuel process.Queue & 0.00 & 0.00 & 0.00 & 0.00 & 0.00 & 0.00 \\
\hline $\begin{array}{l}\text { fitment of exhaust gearbox } \\
\text { process.Queue }\end{array}$ & 4.0273 & 0.75 & 2.7279 & 6.4534 & 0.00 & 83.1203 \\
\hline fitment of fuel tank.Queue & 8.0622 & 1.20 & 6.3412 & 11.4135 & 0.00 & 81.5363 \\
\hline $\begin{array}{l}\text { fitment of soundproof } \\
\text { process.Queue }\end{array}$ & 13.6948 & 1.69 & 8.6745 & 17.4148 & 0.00 & 133.43 \\
\hline $\begin{array}{l}\text { head light battery } \\
\text { box.Queue }\end{array}$ & 5.1110 & 1.44 & 1.8052 & 8.6885 & 0.00 & 62.8799 \\
\hline $\begin{array}{l}\text { mirrors and mudguard } \\
\text { mounting.Queue }\end{array}$ & 5.6557 & 1.47 & 3.2239 & 8.4479 & 0.00 & 103.95 \\
\hline $\begin{array}{l}\text { Preparation of cooling } \\
\text { pack.Queue }\end{array}$ & 5.0466 & 0.76 & 3.6675 & 7.1977 & 0.00 & 83.6119 \\
\hline programming.Queue & 0.00 & 0.00 & 0.00 & 0.00 & 0.00 & 0.00 \\
\hline rear mudguard fitment.Queue & 4.6209 & 0.84 & 3.1434 & 7.2985 & 0.00 & 66.7350 \\
\hline rework process.Queue & 0.00 & 0.00 & 0.00 & 0.00 & 0.00 & 0.00 \\
\hline spare wheel.Queue & 2.0053 & 0.33 & 1.3635 & 2.8869 & 0.00 & 18.3431 \\
\hline tyres.Queue & 5.3109 & 1.06 & 2.0019 & 7.0861 & 0.00 & 63.4186 \\
\hline
\end{tabular}

Figure 4. Waiting time in queue.

\subsection{Improvement of the Final Assembly Line}

\subsubsection{Experimental Design}

The simulation model developed from this research was used to run several experimental designs. This enabled the researcher to visualize the impact to productivity, when entity attributes and assigned resources are changed. The experimentation with independent variables was done on the computer model since it can very disruptive to carry out such experimentation on the actual system. The experimental research design allowed the researcher to control the situation and in so doing it allowed researchers to understand the cause and effect of each in- 
put characteristics. Table 2 shows the scenarios that were tested to establish the output associated with the scenario conditions. Starting with the current status as baseline the simulation was run and the constraint was identified in the simulation. The values at the constraint were modified with due consideration to practical limits and where output improved, these values were adopted as the new baseline. The scenario that yielded the highest output was adopted for implementation.

Figure 5 displays the production output under the baseline conditions and after each of experimental conditions. Scenarios 3 gives the highest output of all the experiments.

The independent variables in the scenario number 3 experimental design, were used to alter the actual system since they yielded the highest results on the computer simulation. The experimentation results show that optimal scenario has production output of 39 trucks. In order to achieve this production output, two operators and two extra machines were added.

Table 2. Different scenarios for improvement.

\begin{tabular}{ll}
\hline $\begin{array}{l}\text { Problem Identification } \\
\text { The bottleneck in engine subassembly, }\end{array}$ & Scenarios \\
$\begin{array}{l}\text { cab preparation and drop, } \\
\text { fitment of fuel and bumper. }\end{array}$ & $\begin{array}{l}\text { What if we add an extra workstation in? } \\
\text { Each process of the four processes? }\end{array}$ \\
$\begin{array}{l}\text { The bottleneck in engine subassembly, } \\
\text { fitment of fuel and bumper. }\end{array}$ & What if we add more operators? \\
$\begin{array}{l}\text { The bottleneck in engine subassembly, } \\
\text { cab preparation and drop, }\end{array}$ & In the stations with longue queue? \\
\begin{tabular}{l} 
fitment of fuel and bumper. \\
\hline
\end{tabular}
\end{tabular}

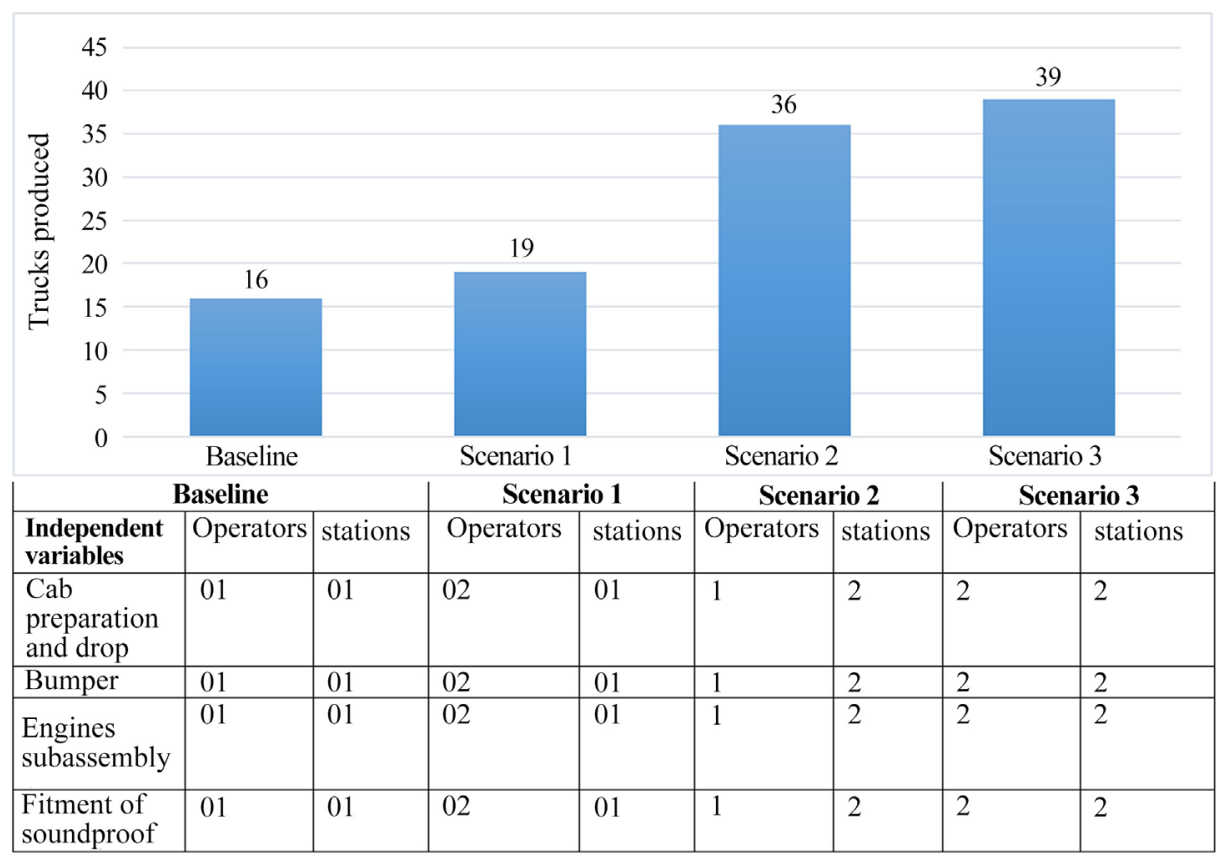

Figure 5. Production output different scenarios. 
Figure 5 shows the improvement model after considering different scenarios. As it is observed, in each workstation with a long queue a supplementary workstation was added. In addition, in each workstation, one more operator was added as well (Figure 6).

\subsubsection{Truck Produced after Optimization}

Figure 7 showed the trucks produced in the final assembly line after optimization. Therefore, as stated in Table 1, three scenarios were considered, and the best scenarios were chosen. The original model, which represents the final assembly

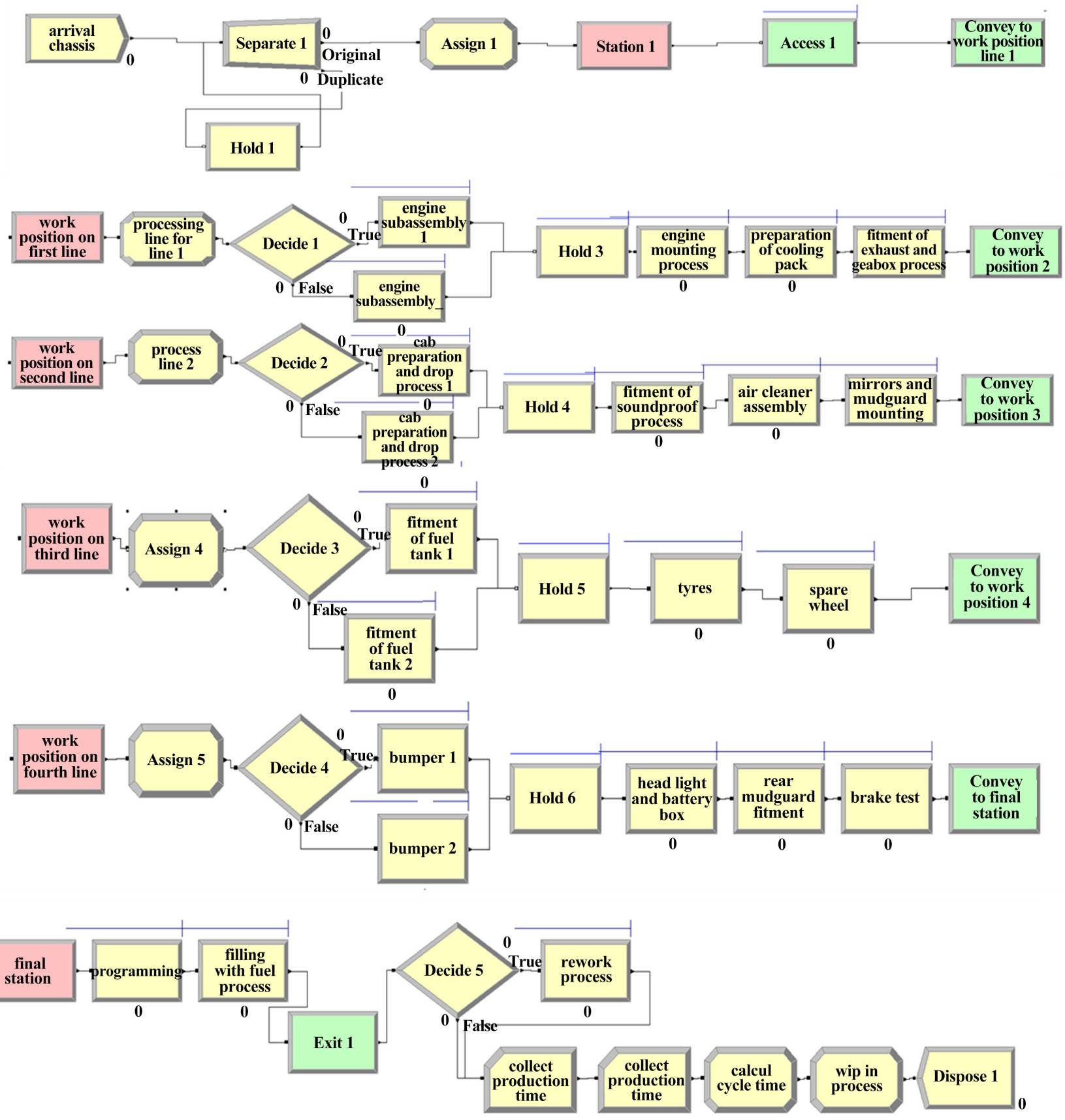

Figure 6. Improvement model (run mode). 


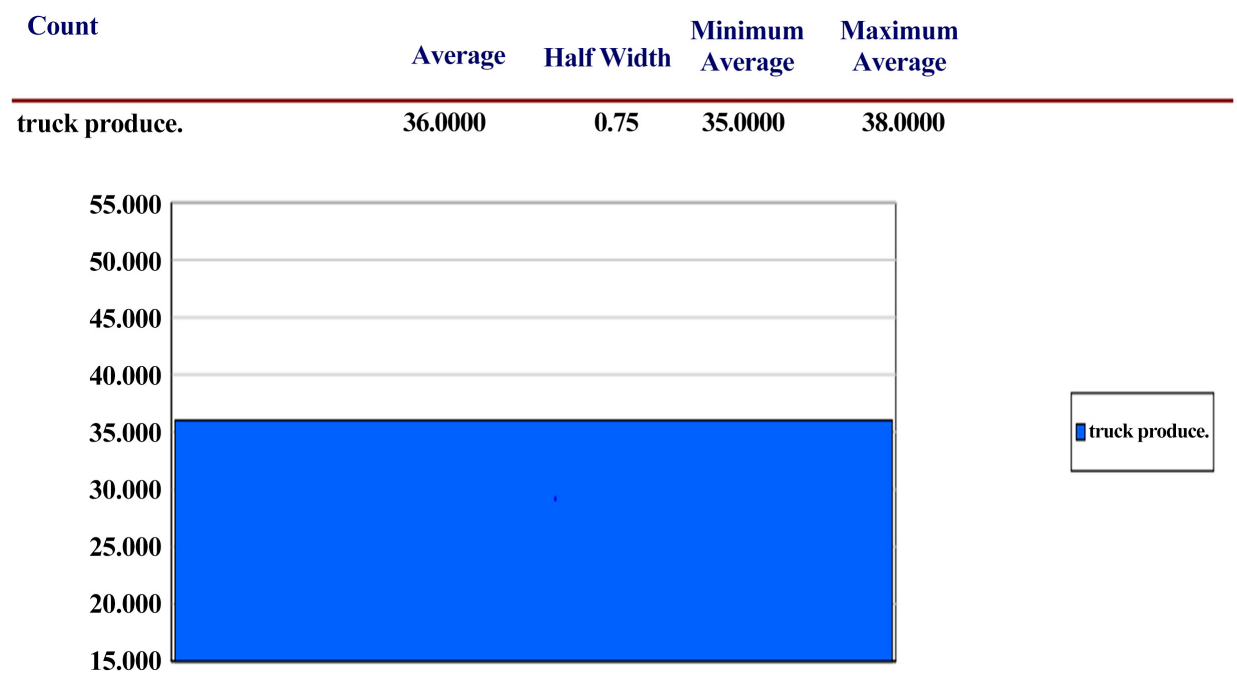

Figure 7. Trucks Produced after optimization.

\section{Queue}

Time

\begin{tabular}{|c|c|c|c|c|c|c|}
\hline Waiting Time & Average & Half Width & $\begin{array}{r}\text { Minimum } \\
\text { Average }\end{array}$ & $\begin{array}{r}\text { Maximum } \\
\text { Average }\end{array}$ & $\begin{array}{l}\text { Minimum } \\
\text { Value }\end{array}$ & $\begin{array}{r}\text { Maximum } \\
\text { Value }\end{array}$ \\
\hline Acces 1. Queues & 51738 & 460 & 506.50 & 527.72 & 0.00 & 720.00 \\
\hline air cleaner assembly.Queue & 4.0224 & 0.58 & 2.7364 & 5.2439 & 0.00 & 95.7080 \\
\hline Brake test.Queue & 2.6965 & 0.45 & 1.5208 & 3.3449 & 0.00 & 63.9489 \\
\hline bumper 1.Queue & 3.7659 & 0.32 & 3.1016 & 4.5493 & 0.00 & 68.3543 \\
\hline bumper 2.Queue & 2.4798 & 0.75 & 1.1475 & 4.2929 & 0.00 & 53.7767 \\
\hline cab preparation and drop process & 3.0960 & 0.70 & 2.3271 & 5.3492 & 0.00 & 51.2529 \\
\hline $\begin{array}{l}\text { 2.Queue } \\
\text { cab process and drop }\end{array}$ & 3.9675 & 0.53 & 2.6515 & 4.8181 & 0.00 & 72.5828 \\
\hline $\begin{array}{l}\text { process I.Queue } \\
\text { check queue.Queue }\end{array}$ & 0.00 & 0.00 & 0.00 & 0.00 & 0.00 & 0.00 \\
\hline engine mounting process .Queue & 5.0863 & 0.47 & 4.2292 & 6.3095 & 0.00 & 79.4060 \\
\hline engine subassembly 1.Queue & 4.2124 & 0.38 & 3.6430 & 5.3269 & 0.00 & 58.5798 \\
\hline engine subassembly 2.Queue & 3.8279 & 0.57 & 2.7585 & 5.3702 & 0.00 & 60.8465 \\
\hline filling with fuel process.Queue & 0.00 & 0.00 & 0.00 & 0.00 & 0.00 & 0.00 \\
\hline $\begin{array}{l}\text { fitment exhaust and gearbox } \\
\text { process.Queue }\end{array}$ & 3.8597 & 0.87 & 2.2901 & 5.4592 & 0.00 & 63.1250 \\
\hline fitment of fuel tank 1. Queue & 0.00 & 0.00 & 0.00 & 0.00 & 0.00 & 0.00 \\
\hline fitment of fuel tank 2.Queue & 2.3673 & 0.31 & 1.6933 & 2.9475 & 0.00 & 45.9213 \\
\hline $\begin{array}{l}\text { fitment of soundproof } \\
\text { process.Queue }\end{array}$ & 4.4205 & 0.60 & 3.2478 & 5.8881 & 0.00 & 72.5839 \\
\hline $\begin{array}{l}\text { head light and battery } \\
\text { box. Oueue }\end{array}$ & 3.2565 & 0.75 & 1.3657 & 4.9705 & 0.00 & 104.21 \\
\hline Hold 3.Queue & 2.4204 & 0.43 & 1.4664 & 3.0264 & 0.00 & 116.90 \\
\hline Hold 4.Queue & 1.6963 & 0.65 & 0.9433 & 3.3832 & 0.00 & 83.5986 \\
\hline Hold 5.Queue & 0.1831 & 0.10 & 0.02843677 & 0.4027 & 0.00 & 30.3504 \\
\hline Hold 6.Queue & 1.0838 & 0.42 & 0.2677 & 2.4073 & 0.00 & 73.4224 \\
\hline $\begin{array}{l}\text { mirrors and mudguard } \\
\text { mounting. Oueue }\end{array}$ & 4.0955 & 0.71 & 1.7056 & 5.2801 & 0.00 & 90.9815 \\
\hline preparation of cooling & 4.9280 & 0.59 & 4.0269 & 6.3283 & 0.00 & 96.9276 \\
\hline programming.Queue & 0.00 & 0.00 & 0.00 & 0.00 & 0.00 & 0.00 \\
\hline rear mudguard fitment.Queue & 3.0801 & 0.36 & 1.9917 & 3.8278 & 0.00 & 81.3905 \\
\hline rework process.Queue & 0.00 & 0.00 & 0.00 & 0.00 & 0.00 & 0.00 \\
\hline spare wheel.Queue & 1.4635 & 0.41 & 0.9690 & 2.7661 & 0.00 & 55.9516 \\
\hline tyres.Queue & 1.7588 & 0.31 & 1.0464 & 2.3017 & 0.00 & 46.1502 \\
\hline
\end{tabular}

Other

Figure 8. Improvement of the queue in the constraints.

line, has 16 outputs. The optimal scenario has an output of 36 trucks produced that lead to the achievement of a $110 \%$ increase in productivity. 


\subsubsection{Queue in the System after Optimization}

Figure 8 shows the queue in the system in terms of waiting time and number waiting after optimization. The waiting time observed in-cab preparation and drop, bumper, engine subassembly, fitment of soundproof has greatly reduced after optimization using scenarios in Table 1 ; the best scenario was to add a parallel workstation and operators. The queue has reduced for the two workstations added and two operators respectively from 14.4 to 3.97 and 3.1, from 13.97 to 3.77 and 2.48 , from 13.00 to 4.21 and 3.83 , from 13.70 to 0.00 and $2.37 \mathrm{mi}$ nutes, with respective average number waiting from $24.87 \%$ to $5 \%$ and $2 \%$, from $17.57 \%$ to $5 \%$ and $0.9 \%$, from $25.91 \%$ to $5 \%$ and $4 \%$, and from $23.39 \%$ to $0.00 \%$ and $3 \%$. We can conclude from the observation there is an improvement and constraint in the system were reduced.

\section{Conclusion}

In conclusion, the research study has demonstrated that arena software is a powerful simulation tool for modelling and productivity improvement. The overall objective of this study was to optimize the productivity of a truck assembly line. Therefore, to achieve this objective, a simulation model was made based on the real system by observing a truck assembly line using arena software. The result of the simulation model showed an output of 16 trucks. But after optimization using different scenarios adding trucks and operators in each workstation where there are constraints, the result showed a great improvement with an output of 36 trucks, which is an improvement of $110 \%$. Also, the queue has reduced for the two workstations added and two operators respectively from 14.4 to 3.97 and 3.1, from 13.97 to 3.77 and 2.48, from 13.00 to 4.21 and 3.83, from 13.70 to 0.00 and 2.37 minutes, with respective average number waiting from $24.87 \%$ to $5 \%$ and $2 \%$, from $17.57 \%$ to $5 \%$ and $0.9 \%$, from $25.91 \%$ to $5 \%$ and $4 \%$, and from $23.39 \%$ to $0.00 \%$ and $3 \%$ observed in-cab preparation and drop, bumper, engine subassembly, fitment of soundproof.

\section{Contribution to the Study}

The study contributes to the ongoing research study on different improvements methods used in automotive industry to make it more competitive in the market. Therefore, through this research study using arena software, it has been demonstrated that arena is a powerful tool for productivity improvement in a truck assembly. This research study has improved the output production up to $144 \%$, and can be easily implemented in a real system.

\section{Suggestions for Further Research}

In conclusion, for visualization using animation, the researcher recommends that commercial arena software be a great help for further study. Also, since the constraint of a production system can shift from one workstation to another, its recommended to simulate the entire process to evaluate the overall performance. 
In addition, due to restrictions of covid-19, it is recommended to test the improvement methods in a real system to evaluate any area of improvement to make it a standard for easy implementation.

\section{Acknowledgements}

I want to take this opportunity to express my sincere gratitude to Africa Union Commission to fund this research study. I also, want to thank my supervisors Prof, Peter N. Muchiri, Dr Patrick Kuloba and Dr. James Kuria Kimotho for their assistance on this study.

\section{Conflicts of Interest}

The authors declare no conflicts of interest regarding the publication of this paper.

\section{References}

[1] Araya Teklay, T., Presented, I.E., Fulfilment, P., Engineering, M. and Stream, I.E. (2018) Efficiency Analysis and Performance Improvement of Bottling Production Line. A Thesis Submitted to the School of Mechanical and Industrial Engineering. Partial Fulfillment of the Requirements for the Degree of Master of Science in Mechanical Eng.

[2] Ndungu, J.N., Muchiri, P.N. and Muguthu, J. (1998) Productivity Improvement of the Manufacturing Processes through Modelling and Simulation Analysis. A Case Study of a Vehicle Assembly Plant in Kenya, 1-7.

[3] Lanna, F. (2013) A Study on Production Productivity Improvement in Food Processing Industries. Jurnal Teknologi, 1, 69-73. https://doi.org/10.11113/jt.v56.60

[4] Svensson, B.O. (2010) Optimisation of Manufacturing Systems Using Time Synchronised Simulation.

[5] Spieckermann, S., Gutenschwager, K., Heinzel, H. and Voß, S. (2014) Simulation-Based Optimization in the Automotive Industry-A Case Study on Body Shop Design.

[6] Tahar, R.B.M. and Adham, A.A.J. (2010) Design and Analysis of Automobiles Manufacturing System Based on Simulation Model. Modern Applied Science, 4, 130. https://doi.org/10.5539/mas.v4n7p130

[7] Jayaraman, A. and Gunal, A.K. Applications of Discrete Event Simulation in the Design of Automotive Powertrain Manufacturing Systems. Winter Simulation Conference, 758-764. https://doi.org/10.1145/268437.268620

[8] Marsudi, M. and Shafeek, H. (2013) The Evaluation of Production Line Performance by Using ARENA-A Case Study. Int. J. Ind. Sci. Eng., 7, 655-659.

https://doi.org/10.3182/20130619-3-RU-3018.00515

[9] Büyüksaatçi Kiriş, S. and Ünal, M. (2020) Evaluating the Performance of the Production Line with Simulation Approach in Meat Processing Industry: A Case from Turkey. Alphanumeric Journal, 8, 1-16. https://doi.org/10.17093/alphanumeric.717667

[10] Dewa, M. and Chidzuu, L. (2013) Managing Bottlenecks. Manual Automotive Assembly Systems Using Discrete Event Simulation, 12, 155-166.

https://doi.org/10.7166/24-2-567 
[11] Ndungu, J.N., et al. (2016) Productivity Improvement of the Manufacturing Processes through Modelling and Simulation Analysis. A Case Study of a Vehicle Assembly Plant in Kenya.

[12] Rawangwong, S., Homkhiew, C., Sani, S., Rodjananugoon, J. and Tehyo, M. (2020) Efficiency Improvement in Assembly Rubber Wooden Toys Using Motion and Times Study and Principles of Ergonomics: A Case Study of a Sample Factory. Princess of Naradhiwas University Journal, 12, 97-112. 